\title{
Quantification of the total amount of black cohosh cycloartanoids by integration of one specific ${ }^{1} \mathrm{H}$ NMR signal
}

Serhat Sezai Çiçek $^{\mathrm{a},{ }^{*}, \text { Ulrich Girreser }^{\mathrm{b}} \text {, and Christian Zidorn }}{ }^{\mathrm{a}}$

${ }^{a}$ Pharmazeutisches Institut, Abteilung Pharmazeutische Biologie, Christian-Albrechts-Universität zu Kiel, Gutenbergstraße 76, 24118 Kiel, Deutschland

b Pharmazeutisches Institut, Abteilung Pharmazeutische und Medizinische Chemie, ChristianAlbrechts-Universität zu Kiel, Gutenbergstraße 76, 24118 Kiel, Deutschland

* Author to whom correspondence should be addressed. E-mail: scicek@pharmazie.uni-kiel.de 


\section{ABSTRACT}

Quantitative analysis is an important field in the quality control of medicinal plants, aiming to determine the amount of pharmacologically active constituents in complex matrices. Often biological effects of herbal drugs are not restricted to single compounds, but are rather caused by a number of often biogenetically related plant metabolites. Depending on the complexity of the analyzed plant extract, conflicts between accuracy, such as total content assays using photometric or colorimetric methods, and comprehensiveness, e.g. quantification of one or a few lead compounds can occur. In this study, we present a qHNMR approach determining the total amount of cycloartanoids in black cohosh (Actaea racemosa) rhizomes. Perdeuterated methanol containing 1,2,4,5-tetrachloro-3-nitrobenzene as an internal standard was used for extraction. Amounts of cycloartanoids were then measured by integrating ${ }^{1} \mathrm{H}$ NMR signals of all cycloartenoids' H-19 exo protons. Due to their unusually low chemical shifts, these signals are well separated from all remaining signals in crude extracts. Thus, accurate (recovery rates of 99.5 to $102.5 \%$ ) and precise (relative standard deviations below $2.5 \%$ ) quantification of cycloartanoids was accomplished. To the best of our knowledge, this is the first example of a quantification of the total amount of a pharmacologically relevant compound class by integration of one ${ }^{1} \mathrm{H}$ NMR signal characteristic for all members of this particular compound class. Additionally, we propose a new term and unit for the evaluation of medicinal plants and herbal medicinal products: the "specific partial amount of substance" of pharmacologically active constituents, indicated in $\mathrm{mmol} / \mathrm{g}$.

Keywords: Actaea racemosa, Cimicifuga racemosa, qNMR, dietary supplements, quality control 


\section{Introduction}

In the last decades, quantitative ${ }^{1} \mathrm{H}$ NMR spectroscopy (qHNMR) evolved into a standard analytical technique $[1,2]$, not only for the determination of compound purities, but also for the analysis of complex natural samples [3]. Enabled by increases in magnetic strength, qHNMR has recently been applied in various areas, such as agricultural chemistry [4], pharmaceutical science [5], forensic science [6], biochemistry \& metabolomics [7], and natural product chemistry [8]. Following quantitative NMR spectroscopic studies on such prominent botanicals as ginkgo (Ginkgo biloba L.), licorice (Glycyrrhiza glabra L.), and red clover (Trifolium pratense L.) [9-11], the current work applies qHNMR to rhizomes and extracts of Actaea racemosa L. [syn.: Cimicifuga racemosa (L.) Nutt.].

Commonly known as black cohosh, A. racemosa has a long history of medical use and is represented in official monographs of many pharmacopoeias [12]. After the first medicinal product was introduced for the therapy of menopausal symptoms more than sixty years ago, the drug was subject of numerous clinical and pharmacological studies $[13,14]$. To this day, both the efficacy and the mechanism of action of black cohosh are still discussed controversially [12-15]. However, triterpenoids contained in the rootstock are often considered to play an important role for its beneficial effects [16-18]. So far, more than 40 triterpenoids of the 9,19-cycloartane type have been isolated from black cohosh (basic structure given in Fig. 1) $[14,19]$.

Due to the complexity of the species' metabolite pattern and the similarity of the different structures, not only clinical trials (patients were in general receiving isopropanolic extracts) [13], but also several pharmacological studies were performed employing alcoholic extracts instead of pure compounds [20-23]. For the same reason, analytical studies on black cohosh triterpenes are challenging. Apart from fingerprint studies to discriminate black cohosh from other Actaea species 
[24-26], HPLC has also been applied for quantification purposes. Of the four HPLC methods described in the literature [27-30], two cover the major triterpenoids occurring in black cohosh rhizomes $[28,30]$, but assessment of the total cycloartane content still has not yet been accomplished.

The present manuscript describes an NMR-based approach and a new strategy in natural product analysis, quantifying a whole compound class by integration of one compound class specific signal; in the case of black cohosh, the signal of the $\mathrm{H}-19$ exo protons of the cyclopropane rings (highlighted in red in Fig. 1).

\section{Materials and methods}

\subsection{Chemical Reagents and Material}

Dried and cut plant material was obtained from Alfred Galke GmbH (Bad Grund, Germany). Deuterated solvents for NMR spectroscopy were purchased from Euriso-top GmbH (Saarbrücken, Germany) and conventional $5 \mathrm{~mm}$ sample tubes were obtained from Rototec-Spintec $\mathrm{GmbH}$ (Griesheim, Germany). LC-MS grade formic acid, 1,2,4,5-tetrachloro-3-nitrobenzene (standard for quantitative NMR) were obtained from Sigma Aldrich Co. (St. Louis, MO, USA). Acetonitrile, methanol, water (all of LC-MS grade), and other (analytical grade) solvents were purchased from VWR International GmbH (Darmstadt, Germany). 0.45 and $0.20 \mu \mathrm{m}$ pore size membrane filters (Chromafil PET-45/25 and PET-20/13) were obtained from Macherey-Nagel GmbH \& Co. KG (Düren, Germany).

\subsection{General experimental procedures}


NMR spectra were recorded using a Bruker Avance III 300 NMR spectrometer with a 5 mm PABBO broad band probe with z gradient. Extract, fractions, and pure compounds were analyzed using a VWR-Hitachi Chromaster Ultra RS equipped with a 6170 binary pump, 6270 autosampler, 6310 column oven, $6430 \mathrm{DAD}$, and a Sederé 100 evaporative light scattering detector using a Phenomenex Luna Omega C18 column (100 x $2.1 \mathrm{~mm}, 1.6 \mu \mathrm{m}$ particle size $)$. MS analysis was carried out with a Shimadzu LCMS 8030 triple quadrupole mass spectrometer using atmospheric pressure chemical ionization. TLC was performed on silica gel 60 F254 plates using dichloromethane-methanol $(85: 15 \mathrm{v} / \mathrm{v})$ as mobile phase and vanillin-sulphuric acid for detection.

\subsection{Extraction and isolation}

Dried and ground rhizomes (700 g) were extracted with acetone using ultrasonication, and the solvent was evaporated under reduced pressure to yield $42 \mathrm{~g}$ of a crude extract. The extract was then subjected to silica gel column chromatography $(50 \times 7.5 \mathrm{~cm})$ and eluted with dichloromethane-methanol (9:1 to 5:5, followed by 100\% methanol) resulting in six fractions (AF). Fraction C (1.98 g) was chromatographed over a silica gel column $(100 \times 3.5 \mathrm{~cm})$ using $n$ hexane-ethyl acetate-methanol (10:10:0.5 to 10:10:3 v/v/v) in a gradient manner, yielding 11 subfractions (C1-C11), of which fraction C9 gave $16.38 \mathrm{mg}$ of actein after crystallization from methanol. Structures of the isolated compounds were elucidated by comparing MS and NMR spectra to literature data [31].

\subsection{NMR measurements}


A stock solution of $10.00 \mathrm{mg} / \mathrm{mL} 1,2,4,5$-tetrachloro-3-nitrobenzene in methanol- $d_{4}$ was prepared and further diluted with methanol- $d_{4}$ into a standard solution of $2.00 \mathrm{mg} / \mathrm{mL}$. For analysis of black cohosh rhizomes $100.0 \mathrm{mg}$ of plant material were extracted with $1000 \mu \mathrm{L}$ of standard solution using ultrasonication for 45 minutes. After 15 minutes of shaking at $200 \mathrm{rpm}$, the solution was directly filtered into the NMR sample tube. For quantification of tablets, equivalents of 26 or $25 \mathrm{mg}$ plant extract were used. Tablets were crushed and sonicated for 45 minutes with $20.00 \mathrm{ml}$ of acetone. After centrifugation at 3,500 rpm, $10.00 \mathrm{ml}$ of the solution were evaporated to dryness. The residue was suspended in $1000 \mu \mathrm{L}$ standard solution and filtered through $0.20 \mu \mathrm{m}$ membrane filters. For purity measurements $2.60 \mathrm{mg}$ of isolated actein was dissolved in $250 \mu \mathrm{L} \mathrm{DMSO}-d_{6}$ and diluted with $100 \mu \mathrm{L}$ of stock solution and $150 \mu \mathrm{L}$ of methanol- $d_{4}$ (actein solution). Thus, equimolar concentrations of actein $(5.20 \mathrm{mg} / \mathrm{mL})$ and 1,2,4,5-tetrachloro-3-nitrobenzene $(2.00 \mathrm{mg} / \mathrm{mL})$ were obtained. Accuracy measurements were accomplished by spiking black cohosh samples with 50 , 100 and $150 \mu \mathrm{L}$ of the actein solution. In order to maintain a concentration of $2.00 \mathrm{mg} / \mathrm{mL} 1,2,4,5-$ tetrachloro-3-nitrobenzene, the volume of standard solution was reduced by the same amount.

${ }^{1} \mathrm{H}$ NMR were recorded at $298 \mathrm{~K}$, the temperature was calibrated with a methanol- $d_{4}$ solution. For each sample automatic tuning and matching of the probe was performed and additionally automatic shimming of the on-axis shims ( $\mathrm{Z}$ to $\mathrm{Z}$ ). The automatic receiver gain adjustment mode was employed. The Bruker Topspin software $2.1 \mathrm{pl} 6$ was used to record 64 scans after 2 dummy scans with a $30^{\circ}$ flip angle corresponding to a pulse width of $3.7 \mu \mathrm{s}$ and $2^{16}(64 \mathrm{k})$ data points were collected with a sweep width of $18 \mathrm{ppm}$, corresponding to an acquisition time of $6.06 \mathrm{~s}$. After optimization the relaxation delay was set to $25 \mathrm{~s}$. The digitization mode was set to digital.

\subsection{NMR data processing}


Data processing was also performed using the Topspin software. The raw fid was zero-filled to $2^{17}(128 \mathrm{k})$ data points before exponential multiplication with a line broadening factor of 1.0 and Fourier transformation. After performing automatic phase correction careful manual adjustment of the spectrum phase was done. For the plant samples the baseline correction was performed manually for the IS in the range of 8.50 and $7.80 \mathrm{ppm}$ and for the cycloartanoids in the range of 0.55 to 0.25 ppm applying only a straight line between the borders, that means only parameters A and $\mathrm{B}$ of the manual baseline correction routine were used. For the standard signal at about 8.15 ppm a signal-to-noise ratio was determined of 250 to 1 , for the extracts' proton signal at $0.45 \mathrm{ppm}$ a signal-to-noise ratio was determined of 420 to 1 . The signals were integrated from 8.30 to 7.90 ppm (1,2,4,5-tetrachloro-3-nitrobenzene) and from 0.55 to $0.30 \mathrm{ppm}$ (cycloartanoids). Due to the use of DMSO- $d_{6}$ as co-solvent for purity and accuracy measurements, slight variations of chemical shifts were observed and integration ranges had to be adapted.

\section{Results and discussion}

\subsection{Selection of NMR solvent and internal standard}

According to the black cohosh monograph of the Pharmacopoeia Europaea (Cimicifugae rhizoma), rhizomes are extracted with a mixture of methanol-water (1:1) using ultrasonication for 45 minutes followed by shaking for another 15 minutes [32]. Thus, black cohosh extracts with different NMR solvents (acetone, chloroform, dimethyl sulfoxide, methanol, pyridine and water) were prepared in the same way and compared to the methanol-water extract by NMR. Of all solvents only methanol was found to quantitatively extract 9,19-cycloartanes (Fig. S1-S8, Table S1). 
As mentioned above, black cohosh triterpenes are characterized by a 9,19-cycloartane scaffold, in which positions 9 and 10 are linked via a methylene group, C-19 (Fig. 1). NMR data of H-19 exo protons of $A$. racemosa triterpenes recorded in pyridine- $d_{5}$ consistently displayed ${ }^{1} \mathrm{H}$ NMR chemical shift values between 0.2 and $0.5 \mathrm{ppm}$ [18].

A closer look at the data reveals two separate clusters in proton shifts. The major cluster, ranging from 0.2 to $0.35 \mathrm{ppm}$, included compounds bearing acteol, shengmanol, and non-hydroxylated cimigenol scaffolds, while the minor cluster, ranging from 0.35 to $0.5 \mathrm{ppm}$, contained $1-\beta$ hydroxylated, $7-\beta$-hydroxylated, and 12- $\beta$-hydroxylated cimigenol scaffolds and scaffolds with a double bond from C-7 to C-8. When measured in methanol- $d_{4}$, both clusters displayed signals in the range between 0.30 and $0.50 \mathrm{ppm}$ and were well separated from all other ${ }^{1} \mathrm{H}$ NMR signals in the crude black cohosh extracts (Fig. 1). H,H-COSY measurements of the methanol extract confirmed that H-19 endo protons of the major cluster, displayed shift values above $0.60 \mathrm{ppm}$, thus not interfering with signals assignable to H-19 exo protons (Fig. 2).

Due to the high extraction potential of methanol and the abundance of various other compounds in black cohosh [14], NMR spectra of crude extracts showed signals for protons up to $7.8 \mathrm{ppm}$. Therefore, a methanol soluble internal standard with higher chemical shifts was warranted. From the commercially available reference standards, only 1,2,4,5-tetrachloro-3-nitrobenzene fulfilled these criteria and was therefore chosen for this study [33].

\subsection{Assay validation}

For assay validation, accuracy, precision, and repeatability were measured. Determination of accuracy was accomplished by spiking black cohosh samples with isolated actein, a major cycloartanoid of A. racemosa. Before, the purity of the isolated compound was determined, using 
the same concentration of standard $(2.00 \mathrm{mg} / \mathrm{mL})$, but using a mixture of methanol- $d_{4}$ and DMSO$d_{6}$, due to the low solubility of pure actein in methanol (Fig. 3). In this way, purity of actein was calculated as $101.9 \pm 1.6 \%$.

For accuracy measurements, black cohosh samples were spiked with different amounts of actein. To achieve this, either 50,100 or $150 \mu \mathrm{L}$ of standard solution were replaced by actein plus internal standard stock solution $(5.20 \mathrm{mg} / \mathrm{mL}$ and $2.00 \mathrm{mg} / \mathrm{mL}$, respectively). This procedure allowed maintaining a constant concentration of internal standard while the concentration of actein and thus the signal of the H-19 exo protons increased (Fig. 4). As the actein solution used for spiking contained $50 \%$ deuterated DMSO, also increasing signals of DMSO- $d_{5}$ were observed in the spectra. Recovery rates ranged from $99.5 \%$ to $102.5 \%$. Mean values of the accuracy measurements are shown in table 1.

Precision measurements included intra- and inter-day precision. Intra-day precision was determined by preparing six samples, each measured once. For inter-day precision another six samples were prepared after one weak and compared to the first six samples. Additionally one of the old samples was measured, here no changes were observed. Repeatability was checked by measuring one sample six times. The content of cycloartanoids was determined as "specific partial amount of substance $(q)$ " (see next section) and is presented in mmol per gram dry plant material (Table 2) using the following equation:

$$
q(X)=\frac{I_{X} \times N_{I S} \times m_{I S} \times P_{I S}}{I_{I S} \times N_{X} \times m_{\text {drug }} \times M_{I S} \times 100}
$$

where $I_{X} / I_{I S}=$ integral of analytes/internal standard, $N_{X} / N_{I S}=$ number of protons from analytes/internal standard, $m_{d r u g}=$ mass of plant material extracted in gram, $m_{I S}=$ mass of internal 
standard in milligram, $M_{I S}=$ molecular weight of internal standard, and $P_{I S}=$ percent purity of reference standard.

\subsection{Specific partial amount of substance}

The measure "specific partial amount of substance" was introduced by the German Institute for Standardization (Deutsches Institut für Normung, Berlin) as "Spezifische Partialstoffmenge $(q)$ " and describes the amount of substance contained in a specified mass [34,35]. Equal to molality, which is used for dissolved substances in a solution, its unit is $\mathrm{mol} / \mathrm{kg}$. However, for medicinal plants and herbal products, the expression $\mathrm{mmol} / \mathrm{g}$ will be more practical, because usually, quantities are given in $\mathrm{mg} / \mathrm{g}$ and percentage of weight, when solid samples are measured, or mg/mL for liquids.

As pharmacological actions take place on a molecular level and are caused by receptor modulations by single molecules, the amount of bioactive substances measured in $\mathrm{mmol} / \mathrm{g}$ is actually more relevant than the amount of particular compounds measured in percent or $\mathrm{mg} / \mathrm{g}$. Furthermore, the amount of substance expressed in $\mathrm{mmol} / \mathrm{g}$ is the only measure of quantity which is unaffected by pharmacokinetic processes occurring in the gastrointestinal tract [36]. This is even more important as these metabolic processes happen before the molecules of interest are absorbed into the circulatory system. Thus, differing molecular weights of the bioactive molecules are resulting, depending on the time the respective biological effect(s) are triggered (due to possible prior hydrolyses, oxidations, etc.).

However, the method presented here can also be used to describe quantities in traditional dimensions, thus presenting a semi-quantitative approach. If this should be needed, we suggest to calculate the amount of 9,19-cycloartanes as 23-epi-26-deoxyactein equivalents. 23-epi-26- 
deoxyactein is a major black cohosh triterpene, which is generally used for the standardization of black cohosh extracts. By multiplying with $660.85 \mathrm{mg} / \mathrm{mmol}$, the specific partial amount of substance (in $\mathrm{mmol} / \mathrm{g}$ ) can be converted into $\mathrm{mg} / \mathrm{g}$, as shown in Table 2 .

\subsection{Analysis of commercial products}

The developed quantitative NMR method was subsequently used to analyze the content of different commercial black cohosh products (CP1-CP4). In order minimize the amount of co-extracted excipients (such as cellulose, silicon dioxide, lactose and magnesium stearate), tablets were crushed and extracted with acetone. After evaporation of the solvent, the residue was re-suspended in the standard solution (methanol- $d_{4}$ containing $2.00 \mathrm{mg} / \mathrm{ml} \mathrm{1,2,4,5-tetrachloro-3-nitrobenzene)}$ and filtered into NMR tubes. Contents of cycloartanoids were again expressed in $\mathrm{mmol} / \mathrm{g}$ and $\mathrm{mg} / \mathrm{g}$ and referenced to the claimed amount of extract per tablet and to the amount of extracted plant material per tablet (Table 3). Additionally, the recommended daily intake (according to the information leaflets) of cycloartanoids was calculated and was given in mmol and $\mathrm{mg}$, respectively.

\section{Conclusion}

Previously published assays were applying HPLC-ELSD and external standards resulting in the quantification of three to eighteen cycloartanoids. Due to the complexity of this compound class and the lack of photometric or colorimetric assays the quantitation of the total amount of black cohosh cycloartanoids (all in all at least forty different compounds) has therefore not been possible.

The present study describes an NMR-based approach, using the chemical shift of the highly shielded H-19 exo protons of the cyclopropane rings. As these signals are well separated from all other ${ }^{1} \mathrm{H}$ NMR signals in the crude black cohosh extract, direct quantification of the total amount 
of this pharmacologically relevant compound class was accomplished. Because of the cumulative signals of the H-19 exo protons in the crude extract, a $300 \mathrm{MHz}$ NMR instrument was sufficient to obtain accurate and precise results. The presented method is equally suited for the analysis of plant material and commercial drug products. Thereby, integration of one specific signal characteristic for all members of a compound class reveals a new quantification strategy in the analysis of complex natural samples.

Moreover, we propose an alternative term for the evaluation of medicinal plants and drug products, the specific partial amount of substance (or partial amount of substance). Using the unit $\mathrm{mmol} / \mathrm{g}$, the partial amount of substance expresses amounts on a molar basis and thus focusses on the pharmacological potential of a medicinal plant or dietary supplement rather than on the mass fractions of their active ingredients. Additionally, the partial amount of substance is not affected by any pharmacokinetic processes and thus represents the same quantity of compounds in the crude extract as well as in the circulatory system.

\section{Funding}

This research did not receive any specific grant from funding agencies in the public, commercial, or not-for-profit sectors. 


\section{Figure captions}

Figure 1: ${ }^{1} \mathrm{H}$ NMR spectrum of deuteromethanolic black cohosh extract containing $2.00 \mathrm{mg} / \mathrm{mL}$ 1,2,4,5-tetrachloro-3-nitrobenzene. Left: structure and signal of 1,2,4,5-tetrachloro-3nitrobenzene. Top right: Basic structure of cycloartanoids, proton (red) and respective signals used for integration. $\mathrm{R} 1=\mathrm{H}$ or $\mathrm{OH}, \mathrm{R} 2=\alpha$-L-arabinopyranoside or $\beta$-D-xylopyranoside or $\mathrm{H}, \mathrm{R} 3=\mathrm{H}$ or $\mathrm{OH}, \mathrm{R} 4=\mathrm{H}$ or $\mathrm{OH}$ or $\mathrm{OAc}, \mathrm{R} 5=\mathrm{H}$ or $\mathrm{OH}$.

Figure 2: Non phase sensitive double quantum filtered H,H-COSY of a black cohosh methanol- $d_{4}$ extract in the region of 3.0 to $0.2 \mathrm{ppm}$ and 0.8 to $0.2 \mathrm{ppm}$ (bottom right).

Figure 3: ${ }^{1} \mathrm{H}$ NMR spectrum of actein in methanol- $\mathrm{d}_{4}$ and DMSO- $d_{6}(1: 1)$ containing $2.00 \mathrm{mg} / \mathrm{mL}$ 1,2,4,5-tetrachloro-3-nitrobenzene. Top left: structure of actein, proton (red) and respective signal used for integration. Bottom left: structure and signal of 1,2,4,5-tetrachloro-3-nitrobenzene.

Figure 4: Overlay of ${ }^{1} \mathrm{H}$ NMR spectra of black cohosh samples containing $2.00 \mathrm{mg} / \mathrm{mL}$ 1,2,4,5tetrachloro-3-nitrobenzene (a) and zoomed signals of internal standard (b), DMSO- $d_{5}$ (c) and H19 exo protons (d). Control (black), low spike (blue), medium spike (green) and high spike (red) are marked by different colors. 


\section{Table 1}

Accuracy (Recovery rates of samples spiked with actein) $(\mathrm{N}=3)$.

\begin{tabular}{lllll}
\hline $\begin{array}{l}\text { Sample concentration } \\
(\mathrm{mmol} / \mathrm{mL})\end{array}$ & $\begin{array}{l}\text { Spiked amount } \\
(\mathrm{mmol})\end{array}$ & $\begin{array}{l}\text { Total concentration } \\
(\mathrm{mmol} / \mathrm{mL})\end{array}$ & $\begin{array}{l}\text { Recovery } \\
(\%)\end{array}$ & $\begin{array}{l}\text { RSD } \\
(\%)\end{array}$ \\
\hline 0.00961446 & 0.000391366 & 0.0101346 & $101.29 \%$ & $1.08 \%$ \\
& 0.000782732 & 0.0104745 & $100.74 \%$ & $1.15 \%$ \\
& 0.001174099 & 0.0109073 & $101.10 \%$ & $0.66 \%$ \\
\hline
\end{tabular}

Table 2

Repeatability and precision (Amounts are expressed in $\mathrm{mmol} / \mathrm{g}$ and $\mathrm{mg} / \mathrm{g}$ plant material).

\begin{tabular}{ccccccccc}
\hline $\mathrm{N}$ & \multicolumn{2}{c}{ Repeatability } & \multicolumn{2}{c}{ Intra-day (day 1) } & \multicolumn{2}{c}{ Intra-day (day 2) } & \multicolumn{2}{c}{ Inter-day $(\mathrm{N}=12)$} \\
& $\mathrm{mmol} / \mathrm{g}$ & $\mathrm{mg} / \mathrm{g}^{*}$ & $\mathrm{mmol} / \mathrm{g}$ & $\mathrm{mg} / \mathrm{g}^{*}$ & $\mathrm{mmol} / \mathrm{g}$ & $\mathrm{mg} / \mathrm{g} *$ & $\mathrm{mmol} / \mathrm{g}$ & $\mathrm{mg} / \mathrm{g}^{*}$ \\
\hline 1 & 0.09751 & 64.35 & 0.09814 & 64.77 & 0.09468 & 62.49 & & \\
2 & 0.09567 & 63.14 & 0.09909 & 65.40 & 0.09303 & 61.40 & & \\
3 & 0.09511 & 62.78 & 0.09505 & 62.73 & 0.09725 & 64.19 & & \\
4 & 0.09541 & 62.97 & 0.09655 & 63.72 & 0.09396 & 62.01 & & \\
5 & 0.09730 & 64.22 & 0.10006 & 66.04 & 0.09482 & 62.58 & & \\
6 & 0.09663 & 63.77 & 0.09666 & 63.79 & 0.09445 & 62.34 & & \\
\hline mean & 0.09627 & 63.54 & 0,09759 & 64.41 & 0.09470 & 62.50 & 0.09614 & 63.46 \\
$\mathrm{SD}$ & 0.00102 & 0.67 & 0,00185 & 1.22 & 0.00141 & 0.93 & 0.00218 & 1.44 \\
$\mathrm{RSD}$ & $1.06 \%$ & \multicolumn{1}{c}{$1.89 \%$} & & $1.49 \%$ & $2.26 \%$ \\
\hline
\end{tabular}

* calculated as 23-epi-26-deoxyactein

Table 3

Analysis of commercial products. Total amounts of cycloartenoids in mmol/g extract and $\mathrm{mg} / \mathrm{g}$ extract, $\mathrm{mmol} / \mathrm{g}$ and $\mathrm{mg} / \mathrm{g}$ of plant material, as well as in mmol and $\mathrm{g}$ according to the recommended daily intake (recommended number of tablets following the respective information leaflets).

\begin{tabular}{cccccccc}
\hline & \multicolumn{2}{c}{ Extract } & \multicolumn{2}{c}{ Plant material } & \multicolumn{2}{c}{ Daily intake } & \multicolumn{2}{c}{ RSD } \\
& $\mathrm{mmol} / \mathrm{g}$ & $\mathrm{mg} / \mathrm{g}^{*}$ & $\mathrm{mmol} / \mathrm{g}$ & $\mathrm{mg} / \mathrm{g}^{*}$ & mmol & $\mathrm{mg}^{*}$ & $(\mathrm{~N}=3)$ \\
\hline $\mathrm{CP} 1$ & 0.25424 & 167.80 & 0.03911 & 25.81 & 0.00165 & 1.09 & $2.39 \%$ \\
$\mathrm{CP} 2$ & 0.18962 & 125.15 & 0.02917 & 19.25 & 0.00123 & 0.81 & $2.83 \%$ \\
$\mathrm{CP} 3$ & 0.31924 & 210.70 & 0.03756 & 24.79 & 0.00160 & 1.05 & $3.66 \%$ \\
$\mathrm{CP} 4$ & 0.21676 & 143.06 & 0.03335 & 22.01 & 0.00141 & 0.93 & $0.74 \%$ \\
\hline
\end{tabular}

* calculated as 23-epi-26-deoxyactein 


\section{References}

[1] G.F. Pauli, T. Gödecke, B.U. Jaki, D.C. Lankin, Quantitative ${ }^{1}$ H NMR. Development and potential of an analytical method: an update, J. Nat. Prod. 75 (2012) 834-851.

[2] G.A. Barding, R. Salditos, C.K. Larive, Quantitative NMR for bioanalysis and metabolomics, Anal. Bioanal. Chem. 404 (2012) 1165-1179.

[3] C. Simmler, J.G. Napolitano, J.B. McAlpine, S.N. Chen, G.F. Pauli, Universal quantitative NMR analysis of complex natural samples, Curr. Opin. Biotechnol. 25 (2014) 51-59.

[4] O. Frank, J.K. Kreissl, A. Daschner, T.J. Hofmann, Accurate determination of reference materials and natural isolates by means of quantitative (1)h NMR spectroscopy, Agric. Food. Chem. 62 (2014) 2506-2515.

[5] G.K. Webster, S. Kumar, Expanding the analytical toolbox: pharmaceutical application of quantitative NMR, Anal. Chem. 86 (2014) 11474-11480.

[6] S.J. Dunne, J.P. Rosengren-Holmberg, Quantification of synthetic cannabinoids in herbal smoking blends using NMR, Drug. Test. Anal. 9 (2017) 734-743.

[7] G. Wilder, L.J. Dreier, Measuring protein concentrations by NMR spectroscopy, Am. Chem. Soc. 128 (2006) 2571-2576.

[8] G.F. Pauli, B.U. Jaki, D.C. Lankin, Quantitative ${ }^{1} \mathrm{H}$ NMR: development and potential of a method for natural products analysis, J. Nat. Prod. 68 (2004) 133-149.

[9] J.G. Napolitano, T. Gödecke, M.F. Rodríguez, B.U. Jaki, S.H. Chen, D.C. Lankin, G.F. Pauli, The tandem of full spin analysis and qHNMR for the quality control of botanicals exemplified with Gingko biloba, J. Nat. Prod. 75 (2012) 238-248. 
[10] C. Simmler, D. Nikolic, D.C. Lankin, Y. Yang, J.B. Friese, R.B. van Breemen, A. Lecomte, C. Le Quemener, G. Audo, G.F. Pauli, Orthogonal analysis underscores the relevance of primary and secondary metabolites in licorice, J. Nat. Prod. 77 (2014) 1806-1816.

[11] R.S. Phansalkar, C. Simmer, J. Bisson, S.H. Chen, D.C. Lankin, J.B. McAlpine, M. Niemitz, G.F. Pauli, Evolution of quantitative measures in NMR: quantum mechanical qHNMR advances chemical standardization of a red clover (Trifolium pratense) extract, J. Nat. Prod. 80 (2017) 634647.

[12] A.M. Beer, R. Osmers, J. Schnitker, W. Bai, A.O. Mueck, H. Meden, Efficacy of black cohosh (Cimicifuga racemosa) medicines for treatment of menopausal symptoms - comments on major statements of the Cochrane Collaboration report 2012 "black cohosh (Cimicifuga spp.) for menopausal symptoms (review)", Gynecol. Endocrinol. 29 (2013) 1022-1025.

[13] H.H. Henneicke-von Zepelin, 60 years of Cimicifuga racemosa medicinal products: Clinical research milestones, current study findings and current development, Wien. Med. Wochenschr. 167 (2017) 147-159.

[14] F. Qiu, J.B. McAlpine, E.C. Krause, S.N. Chen, G.F. Pauli, Pharmacognosy of black cohosh: the phytochemical and biological profile of a major botanical dietary supplement, in: A.D. Kinghorn, H. Falk, J. Kobayashi (Eds.), Progress in the Chemistry of Organic Natural Products, Springer, Vienna/New York, 2014, pp. 1-68.

[15] M.J. Leach, V. Moore, Black cohosh (Cimicifuga spp.) for menopausal symptoms, Cochrane Database Syst. Rev., 2012, DOI: 10.1002/14651858.CD007244.pub2 
[16] S.S. Cicek, S. Khom, B. Taferner, S. Hering, H. Stuppner, Bioactivity-guided isolation of GABA(A) receptor modulating constituents from the rhizomes of Actaea racemosa, J. Nat. Prod. 73 (2010) 2024-2028.

[17] B. Strommer, S. Khom, I. Kastenberger, S.S. Cicek, H. Stuppner, C. Schwarzer, S. Hering, A cycloartane glycoside derived from Actaea racemosa L. modulates GABAA receptors and induces pronounced sedation in mice, J. Pharmacol. Exp. Ther. 351 (2014) 234-242.

[18] Y. Su, W.C. Chi, L. Wu, Q.H. Wang, H.X. Kuang, Photochemistry and pharmacology of 9, 19-cyclolanostane glycosides isolated from genus Cimicifuga, Chin. J. Nat. Med.14 (2016) 721731.

[19] F. Qiu, J.B. McAlpine, D.C. Lankin, I. Burton, T. Karakach, N.R. Farnsworth, S.H. Chen, G.F. Pauli, Dereplication, residual complexity, and rational naming: the case of the Actaea triterpenes, J. Nat. Prod. 75 (2011) 432-443.

[20] L.S. Einbond, M. Soffritti, D. Degli Esposti, H.A. Wu, E. Tibaldi, M. Lauriola, K. He, T. Park, T. Su, L. Huggins, X.M. Wang, M. Roller, R. Brennan, Pharmacological mechanisms of black cohosh in Sprague-Dawley rats, Fitoterapia 83 (2012) 461-468.

[21] J.H. Li, T. Gödecke, S.N. Chen, A. Imai, D.C. Lankin, N.R. Farnsworth, G.F. Pauli, R. van Breemen, D. Nikolic, In vitro metabolic interactions between black cohosh (Cimicifuga racemosa) and tamoxifen via inhibition of cytochromes P450 2D6 and 3A4, Xenobiotica 41 (2011) 10211030. 
[22] E.Y. Kim, Y.J. Lee, M.R.J. Rhyu, Black cohosh (Cimicifuga racemosa) relaxes the isolated rat thoracic aorta through endothelium-dependent and -independent mechanisms, J. Ethnopharmacol. 138 (2011) 537-542.

[23] X.Y. Ma, H. Zhang, K. Wang, L.Y. Yang, L.H. Qin, W.P. Bai, Y.F. Guan, J. Jia, J.H. Kang, C.M. Zhou, Effects of an isopropanolic-aqueous black cohosh extract on central body temperature of ovariectomized rats, J. Ethnopharmacol. 138 (2011) 156-161.

[24] B. Jiang, F. Kronenberg, P. Nuntanakorn, M.H. Qiu, E.J. Kennelly, Evaluation of the botanical authenticity and phytochemical profile of black cohosh products by high-performance liquid chromatography with selected ion monitoring liquid chromatography-mass spectrometry, J. Agric. Food. Chem. 54 (2006) 3242-3253.

[25] K. He, G.F. Pauli, B. Zheng, H. Wang, N. Bai, T. Peng, M. Roller, Q. Zheng, Cimicifuga species identification by high performance liquid chromatography-photodiode array/mass spectrometric/evaporative light scattering detection for quality control of black cohosh products, J. Chromatogr. A 1112 (2006) 241-254.

[26] C. Ma, A.R. Kavalier, B. Jiang, E.J. Kennelly, Metabolic profiling of Actaea species extracts using high performance liquid chromatography coupled with electrospray ionization time-of-flight mass spectrometry, J. Chromatogr. A 1218 (2011) 1461-1476.

[27] M. Ganzera, E. Bedir, I.A. Khan, Separation of Cimicifuga racemosa triterpene glycosides by reversed phase high performance liquid chromatography and evaporative light scattering detection, Chromatographia 52 (2000) 301-304. 
[28] W. Li, S. Chen, D. Fabricant, C.K. Angerhofer, H.H.S. Fong, N.R. Farnsworth, J.F. Fitzloff, High-performance liquid chromatographic analysis of Black Cohosh (Cimicifuga racemosa) constituents with in-line evaporative light scattering and photodiode array detection, Anal. Chim. Acta 471 (2002) 61-75.

[29] B. Avula, Y.H. Wang, T.J. Smillie, I.A. Khan, Quantitative determination of triterpenoids and formononetin in rhizomes of black cohosh (Actaea racemosa) and dietary supplements by using UPLC-UV/ELS detection and identification by UPLC-MS, Planta Med. 75 (2009) 381-386.

[30] S.S. Cicek, A. Aberham, M. Ganzera, H. Stuppner, Quantitative analysis of cycloartane glycosides in black cohosh rhizomes and dietary supplements by RRLC-ELSD and RRLC-qTOFMS, Anal. Bioanal. Chem. 400 (2011) 2597-2605.

[31] A. Kusano, M. Takahira, M. Shibano, Y. In, T. Ishida, T. Miyase, G. Kusano, Studies on the constituents of Cimicifuga species. XX. Absolute stereostructures of cimicifugoside and actein from Cimicifuga simplex WORMSK., Chem. Pharm. Bull. 46 (1998) 467-472.

[32] European Pharmacopoeia, eighth ed., European Directorate for the Quality of Medicines \& Health Care (EDQM), Strasbourg, 2014, pp. 1833-1836.

[33] https://www.sigmaaldrich.com/analytical-chromatography/analytical-standards/applicationarea-technique/organiccrm.html (accessed 24 January 2018).

[34] P. Kurzweil, Das Vieweg Einheiten-Lexikon: Begriffe, Formeln und Konstanten aus Naturwissenschaften, Technik und Medizin, $2^{\text {nd }}$ ed., Springer Vieweg, Wiesbaden, 2013, p. 372.

[35] J. Graßmuck, K.W. Houben, R.M. Zollinger, DIN-Normen in der Verfahrenstechnik: Ein Leitfaden der technischen Regeln und Vorschriften, $2^{\text {nd }}$ ed., Springer Vieweg, Wiesbaden, 2014, p. 17. 
[36] Y. Li, Y. Peng, M. Wang, P. Tu, X. Li, Human gastrointestinal metabolism of the Cistanches Herba water extract in vitro: Elucidation of the metabolic profile based on comprehensive metabolite identification in gastric juice, intestinal juice, human intestinal bacteria, and intestinal microsomes, J. Agric. Food Chem. 65 (2017) 7447-7456. 